BULLETIN Bulletin hispanique

HISPANIQUE Université Michel de Montaigne Bordeaux

119-1 | 2017

Autorité et pouvoir dans le théâtre du Siècle d'Or

\title{
La ciudad de Nápoles en dos comedias de Tirso de Molina y el poder del teatro
}

\section{Enrica Cancelliere}

\section{(2) OpenEdition \\ 12 Journals}

Edición electrónica

URL: http://journals.openedition.org/bulletinhispanique/4772

DOI: 10.4000/bulletinhispanique.4772

ISBN: 979-10-300-0142-6

ISSN: 1775-3821

Editor

Presses universitaires de Bordeaux

Edición impresa

Fecha de publicación: 15 junio 2017

Paginación: 89-100

ISBN: 979-10-300-0141-9

ISSN: 0007-4640

\section{Referencia electrónica}

Enrica Cancelliere, «La ciudad de Nápoles en dos comedias de Tirso de Molina y el poder del teatro », Bulletin hispanique [En línea], 119-1 | 2017, Publicado el 15 junio 2020, consultado el 11 septiembre 2020. URL : http://journals.openedition.org/bulletinhispanique/4772 ; DOI : https://doi.org/10.4000/ bulletinhispanique.4772 


\title{
La ciudad de Nápoles en dos comedias de Tirso de Molina y el poder del teatro
}

\author{
Enrica CANCELliere \\ Università di Palermo
}

Dans cet article est étudiée la dimension métaphorique de la ville de Naples, avec ses rues, ses places et ses environs, comme espace privilégié d'une série de configurations rituelles qui sous-tendent l'action et les personnages de El burlador de Sevilla et El condenado por desconfiado, deux des œuvres majeures généralement attribuées à Tirso de Molina. Les théâtres de Naples (de palais et populaires), la choréographie ou l'onomastique, liée aux masques du théâtre napolitain, illustrent le pouvoir symbolique de certaines structures.

Mots-clés: Tirso de Molina, symbolisme, ritualisation, Naples.

El artículo estudia las dimensiones metafóricas de la ciudad de Nápoles, sus calles, plazas y cercanías, como ámbito de una serie de configuraciones rituales que cimentan la acción y personajes del El burlador de Sevilla y El condenado por desconfiado, dos de las principales obras generalmente atribuidas a Tirso de Molina. Los teatros de Nápoles (palaciegos y populares), detalles corográficos o la onomástica de los personajes en relación con las máscaras del teatro napolitano, ilustran el poder de ciertas estructuras simbólicas.

Palabras clave: Tirso de Molina, simbolismo, ritualización, Nápoles.

This article studies the metaphoric dimensions of the city of Naples, its streets, squares and surroundings, as a privileged space of ritual configurations, underlying the action and characters of "El Burlador de Sevilla" and "El Condenado por Desconfiado", two of the major works generally attributed to Tirso de Molina. We also discuss the possibilities of the theatres in Naples (palatial and popular), the details of these performances, chorographic details, etc., in relation to the masks of the Neapolitan theatre, as examples of the power of certain symbolic structures.

Keywords: Tirso de Molina, symbolism, ritualization, Naples. 
$\mathrm{E}$ s muy verosímil que El burlador de Sevilla se estrenara en 1625 en el nuevo y espléndido Palacio Real de Nápoles, el mismo en el que se desarrollan las primeras escenas de la comedia.

El público de la corte, acostumbrado a múltiples variedades de reflejos especulares entre el escenario y el público, se habría dado cuenta de que el poeta y la prestigiosa compañía de Pedro Osorio -cuyos actores representaban exhibiendo los estilos vestimentarios cortesanos- activaban un mecanismo de cajas chinas en el cual ninguno de los presentes podía eximirse de aparecer al mismo tiempo espectador y actor.

El placer del «teatro en el teatro» era característico de los gustos de la época y el comienzo del Burlador estaba dispuesto precisamente para fascinar y a la vez celebrar aquella corte en la cual todos, sin duda, estaban convencidos por su frecuentación del espectáculo teatral de que la vida era como el teatro, y la comedia como la vida, y más aún, de que el teatro mostraba la verdad de la vida, ilusoria y efímera.

Se pudiera objetar que Tirso ambienta las aventuras del gran seductor en el trescientos, durante el reinado en Castilla y León de Alfonso XI, que había fijado su casa real en Sevilla. En este caso el Palacio Real napolitano de las primeras escenas correspondería, en cambio, al angevino, y más tarde aragonés, denominado "Castel Nuovo». Pero es evidente que se trata de una ambientación ficticia, que permite al autor ciertas ironías sin riesgo de ser acusado de satírico. De hecho, el napolitano "Castel Nuovo» no tiene los balcones que son necesarios para la acción en su perímetro exterior de fortaleza torreada. El rey don Juan de Portugal, que reinó en el siglo XV, recordado por don Gonzalo de Ulloa ${ }^{1}$, es posterior al rey Alfonso. Otros personajes y familias ilustres se pueden rastrear en otras épocas y en general no responden a las características que suelen atribuírseles. A Don Pedro Tenorio, embajador de Espańa, el rey de Nápoles le encarga arrestar al culpable del ultraje hecho a Isabela, cosa realmente imposible en el reino aragonés de Nápoles, pero posible en el Virreinato. En suma, el autor ha enmascarado hábilmente, con elementos seudohistóricos la ambientación real de la comedia en su época coetánea, hasta el punto que Francisco Rico sitúa aventuras, personajes y ambiente social de nuestro singular héroe en el siglo XVII, como ha hecho buena parte de la crítica.

Las primeras escenas se representan todas entre puertas abiertas, entreabiertas y semicerradas, con luces vivas y apagadas, en una penumbra que contrapone luz y oscuridad, como si en el vasto espacio de la sala palaciega, sobre las tablas, se dispusiera un virtual tablero de ajedrez sobre cuyos escaques se movieran los peones de la ficción; la alternancia de luz y oscuridad protege y desvela a la par la ambigüedad de los actantes que son los que creen ser y los que fingen ser.

Dicen en el comienzo Isabela y don Juan:

1. Tirso de Molina, El Burlador de Sevilla, ed. de Ignacio Arellano, Madrid, Espasa Calpe, 1993, Jornada I, vv. 698-699. Cito de esta edición. 


$\begin{array}{ll}\text { ISABELA } & \begin{array}{l}\text { Quiero sacar } \\ \text { una luz. }\end{array} \\ \begin{array}{l}\text { DON JUAN } \\ \text { ISABELA }\end{array} & \begin{array}{l}\text { Para que el alma dé fe qué? } \\ \text { del bien que llego a gozar. }\end{array} \\ \text { DON JUAN } & \begin{array}{l}\text { Matarete la luz yo } \\ {[\ldots]}\end{array} \\ \text { ISABELA } & \begin{array}{l}\text { ¡Ah, cielo! ¿Quién eres, hombre? } \\ \text { DON JUAN }\end{array} \\ \text { ¿Quién soy? Un hombre sin nombre. }\end{array}$

Nótese la paronomasia hombre-nombre que pliega la lengua a la ambigüedad de los significantes.

Del mismo modo el soberano, poco después, llega con un candelabro en la mano y una vela encendida, pero no será capaz siquiera de conocer al que tiene delante, de manera que, burlándose de la autoridad real, don Juan no dudará en responder a las indagaciones del rey sobre la identidad de los protagonistas:

\section{¿Quién ha de ser? \\ Un hombre y una mujer. ${ }^{3}$}

Pero ¿quién es, pues, este soberano sino el virrey de Nápoles, el mismo que suele asistir a los espectáculos en el nuevo palacio?

A la luz de este juego de espejos engañosos -y «luz» es el término exacto tanto en sentido literal como metafórico-asume particular relieve el tema metateatral de fondo, que consiste en el reiterado juego de disfraz del protagonista que, según Giovanni Macchia, representa tout court la instancia del actor que goza disfrazándose y asumiendo papeles ajenos, de modo que podemos decir que el juego de la ficción lo complace tanto como la conquista amorosa: «Se hace pasar por el duque Octavio para gozar a Isabel y se hace pasar por el marqués de la Mota para gozar a Ana» ("Si traveste da duca Ottavio e ama Isabella, si traveste da marchese della Mota per amare Anna [...]») .

Y puesto que semejante juego se desenvuelve entre la polaridad de la vida -las empresas amorosas del protagonista- y de la muerte -la terrorífica estatua de piedra que vuelve de entre los muertos para el banquete macabro- he aquí que el teatro evidencia toda la ritualidad propiciatoria de sus orígenes. Veremos enseguida en qué manera todo esto se relaciona con la ciudad de Nápoles, considerada por Tirso en sus potencialidades simbólicas y metafóricas.

En este contexto el valor de don Juan es una demostración de temeridad que se manifiesta en su agresión al orden totémico neotribal del aparato estatal absolutista: del ultraje al rey hasta el sacrilegio ante la estatua que encarna el principio de la Paternidad absoluta.

2. Ibid, vv. 9-15.

3. Ibid, vv. 22-23.

4. Giovanni Macchia, a cura di, Enciclopedia dello Spettacolo, vol. IV, voce: «Don Giovanni», Roma, UNEDI, 1975. (trad. cast. de la autora). Del mismo autor véase también, Vita, avventure e morte di Don Giovanni, Torino, Einaudi, 1978. 
Arellano ${ }^{5}$, sobre el tema fundamental de la rebelión edípica de don Juan, ha insistido sobre el valor de prototipo de la comedia de Tirso, en relación con la literatura y el teatro futuro, musical o no.

La primera afrenta que comete el burlador es más grave, porque quebranta un espacio tabú: Nápoles, el Palacio. Por otro lado el mismo rey de España en persona procederá después a sacralizar como totem patriarcal la estatua de don Gonzalo.

Resumiendo, un joven antihéroe disoluto ofende a un padre y a un tío afectuosos, a una serie de nobles entre los que se halla el desdichado don Gonzalo -al que agravia vivo y en efigie-, y a dos autoridades reales de Nápoles y España: más que suficiente para que el Padre eterno deje a un lado su consustancial Amor.

Suponer que en el fondo se trate de una representación propiciatoria del conflicto real generacional -evoquemos a Frazer ${ }^{6}$ - y del freudiano tabú de los muertos, y que implica el disfraz chamánico del primer actor poseedor del «mana», es una tesis que halla respaldo en estudios específicos de Otto Rank ${ }^{7}$ y Mauricio $\mathrm{Molho}^{8}$. Este motivo totémico regresa en una época cuyas jerarquías sociales y religiosas reproducen en los Estados absolutistas, en sus estructuras y rituales, las manifestaciones simbólico-ideológicas de la cultura tribal, según lo que observa Roland Barthes en Sur Racine?

Que se hayan documentado en octubre de 1625 representaciones del Burlador en el teatro de San Bartolomeo no invalida la hipótesis de su estreno en el Palacio, ya que era corriente que espectáculos de diversas categorías, después de su estreno en los espacios palaciegos de Fontana, pasaran a un espacio público: el intercambio de eventos teatrales entre Palacio y los escenarios públicos más prestigiosos era normal. El teatro de San Bartolomeo, el más importante de Nápoles junto a la más antigua sala de San Giorgio dei Genovesi y a su rival de San Giovanni dei Fiorentini, alojaba juntamente con la "comedia española» -es decir, la comedia por antonomasia y con compañías españolas- a las representaciones de la Commedia dell'Arte, y también a las fiestas pastoriles y églogas piscatorias.

Pero aun cuando la representación del Burlador en Palacio no hubiera tenido lugar, la cercanía de los espacios en el territorio urbano y la presencia de los nobles en los palcos del San Bartolomeo, seguirían apelando a la fascinación del exploit metateatral. Colocar el comienzo de una comedia en la misma ciudad en que tenía lugar la representación era una moda que fungía como homenaje al público y mecanismo de participación para introducirlo en el juego escénico especular.

5. Ignacio Arellano, ed. cit.

6. James Frazer, Il ramo d'oro, Torino, Einaudi, 1950.

7. Otto Rank, Die Don Juan Gestalt, Leipzig, 1924.

8. Mauricio Molho, Mitologías. Don Juan. Segismundo, Madrid, Siglo XXI, 1993.

9. Roland Barthes, «L'uomo raciniano», Saggi critici, Torino, Einaudi, 1972, pp. 141-148. 
Asimismo merece la pena apuntar que en el nuevo y admirable Palacio Real, terminado en 1602, la Sala Grande se dedicaba a espectáculos de variados géneros. Seguramente los fastos de la Sala Grande habían llegado a conocimiento de Tirso y también del famoso Roque de Figueroa en 1636, fecha de la reposición napolitana del Burlador.

No hay duda de que las siete primeras escenas de la comedia se desarrollan en una vasta sala palaciega sobre la cual se abren las puertas de las habitaciones privadas de los nobles, mientras amplios balcones sobresalen hacia el espacio externo, probablemente los jardines reales, puesto que don Juan se arroja de un balcón para escapar al arresto después del atroz insulto que comete contra el honor de la duquesa Isabela. La identificación del lugar se precisa en una intervención de don Pedro Tenorio:

$$
\begin{aligned}
& \text { Di, vil, ¿̨no bastó emprender } \\
& \text { con ira y con fuerza extraña } \\
& \text { tan gran traición en España } \\
& \text { con otra noble mujer, } \\
& \text { sino en Nápoles también } \\
& \text { y en el palacio real, } \\
& \text { con mujer tan principal? }{ }^{10}
\end{aligned}
$$

Es posible que esta sala-que se puede imaginar de amplias proporciones, pues por ella cruzan otros personajes que salen por las puertas, el mismo soberano y guardias que pretenden sin éxito detener a don Juan- pueda identificarse con la famosa Sala Grande destinada a representaciones de la Corte. En el lugar ideal de la ficción y la ilusión fingen y representan todos, no solo don Juan con su disfraz, sino también don Pedro, que protege la fuga de su sobrino y le atribuye el hecho al duque Octavio, Isabela, que miente sobre lo sucedido; y hasta el rey -o virrey- que elude la indagación del escabroso suceso, fingiendo creer la versión de Isabel y don Pedro.

La Corte es, por consiguiente, el reino del teatro y de las ficciones vivientes, bajo la mirada estupefacta y escéptica de los criados.

Podría argumentarse que no hay testimonios de que Tirso viajara nunca a Nápoles, y dudar de que conociera el Palacio Real. Pero -consideradas otras precisas referencias de las dos comedias «napolitanas» que comentamos, $E l$ burlador de Sevilla y El condenado por desconfiado- se puede suponer que el autor haya imaginado con bastante fundamento la nueva realidad urbana, social, antropológica-cultural de la metrópoli mediterránea en su desarrollo entre manierismo y barroco. Desarrollo relacionado con los famosos trabajos del arquitecto real Domenico Fontana. Por lo demás la correspondencia entre los lugares descritos en sus comedias y los reales era para Tirso un recurso destinado a conferir realismo y proporcionar determinadas caracterizaciones de conducta y lenguaje a peripecias y espacios, se tratara de Sevilla, Madrid, Toledo 
o Lisboa. Nápoles, pues, sobre los rasgos de la ciudad real, puede construirse en la poesía tirsiana como una ciudad metafórica, metrópoli mediterránea en la cual la vida se despliega en continuas contradicciones.

Pero el lugar de la acción no está precisado solo por la mención textual explícita. Existe también un territorio connotativo que puede desprenderse de las características lingüísticas y antropológicas de los personajes, e incluso de la evocación de géneros literarios y artísticos propios de un determinado patrimonio cultural. Tirso evoca tales connotaciones cuando desea sugerir un territorio a través de sus potencialidades metafóricas.

No es casualidad, ciertamente, que tres de las cuatro mujeres víctimas del Burlador tengan alguna relación con Nápoles, dejando a un lado el lugar en el cual se encuentran.

En lo que se refiere a Isabel, Arellano ${ }^{11}$ ha subrayado su condición lasciva y su inclinación al enredo que se manifiestan en la profanación del palacio real, y en su falsa acusación contra el inocente Octavio. "Isabela se entrega al que ella cree Octavio, profanado el palacio del rey, impulsada por la lascivia. No hay en ella una gran pasión ni siente un gran amor por Octavio. Su cinismo se hace evidente cuando permite que acusen al galán pensando utilizar en su beneficio la presión del rey» ${ }^{12}$.

Ahora bien, Isabella es en la Commedia dell'Arte el nombre de una máscara femenina que corresponde al papel (aristocrático o servil) de la Innamorata. A partir de ahí, a través de una abundante serie de Scenari, el personaje se va definiendo en el papel de la 'criada', central en la ópera bufa napolitana.

Cuando Tirso escribe El Burlador, Isabella es una máscara habitual en los teatros napolitanos, donde la Commedia dell'Arte se representa continuamente en un momento de gran éxito junto a las emergentes pulcinellate. La Commedia dell'Arte, pues, suele representar a Isabella en el mismo teatro que acoge las dos primeras puestas en escena del Burlador. Se advierte la audacia y la ironía con la que Tirso introduce una máscara femenina de tanta connotación erótica entre los personajes de la Commedia Alta y exactamente en el episodio napolitano, asimilando en la práctica la intriga del Palacio Real a una representación del teatro popular.

Pues no hay duda de que se trata de esto: los lazzi de los graciosos ligan a Isabel con la máscara dell'Arte adaptando el tópico juego escabroso que relaciona a la bella dama noble, aristocráticamente vestida y mostrada sin máscara, con las máscaras serviles que osan profanar aquel icono con su lenguaje alusivo y la grosera gestualidad del subtexto. Así Ripio:

Dando dije, porque al dar no hay cosa que se iguale;

11. Ignacio Arellano, ed. cit.

12. Véase Laura Dolfi, «La "mujer burlada": honor e invención en la comedia de enredo", en Laura Dolfi (a cura di), Tirso de Molina: immagine e rappresentazione, Napoli, Edizioni Scientifiche Italiane, 1991, pp. 135-185. 
y si no, a Isabela dale,

a ver si sabe tomar. ${ }^{13}$

Y más tarde Catalinón aumenta la dosis:

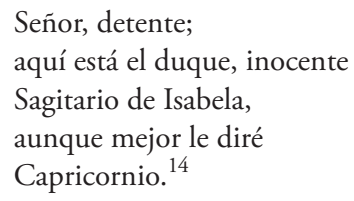

El personaje de Tisbea, en la égloga piscatoria que sigue al episodio de Nápoles, aparece en el litoral cercano a Tarragona, cargado de connotaciones eminentemente humanísticas y literarias más que realistas. La muchacha ya desde su primera aparición, se explaya en un monólogo construido según códigos pastoriles y piscatorios que se convierten en metáforas de la Corte ${ }^{15}$.

Además, desde su comienzo, la égloga poética «Yo, de cuantas el mar...» evoca un teatro de mar, la escenografía más preciada de los arquitectos, empresarios y público, por sus muchas maravillas, y practicada preferentemente en Italia, tanto en los teatros de Corte como en los populares de las Stanze partenopeas. Por otro lado la boga de las escenografías fastuosas y las mutaciones tenía un desarrollo propio en Nápoles desde las famosas fiestas de la Corte de Federico de Aragón, en las que se representaban las églogas de Sannazzaro, de Aquilano y otros.

En el ámbito del clima humanístico napolitano que tenía su fulcro en la Academia de Pontano, Sannazzaro, Actius Syncerus, había adaptado la Piscatoria latina. Fue luego imitado por Bernardino Rota en el siglo XVI con catorce piezas piscatorias en lengua vulgar, y por Tansillo, Ongaro -que sitúa en ambiente marino su reformulación de Aminta-, y otros.

Inmediatamente el melodrama, con sus maravillosas tramoyas, sobre todo las de «escenas de mar», se convertirá en el principal género de los teatros más prestigiosos. Pero en las primeras tres décadas del XVII, la Bella Adriana, nativa de Posillipo y hermana de Giambattista Basile, causa furor en las cortes del centro de Italia, y en Europa, con su sublime canto, a menudo de tema piscatorio, que le valió ser casi divinizada por Marino, Stigliani, Chiabrera o Monteverdi. Todo esto explica por qué el litoral desde Mergellina -patria del Sannazzaro-, a Sorrento - patria del Tasso-, se pudo convertir en el imaginario de los humanistas del primer seiscientos en una nueva Arcadia. Tirso no escapa a esa fascinación: he ahí el verdadero motivo -que es la evocación de un virtual territorio literario y musical- de la égloga piscatoria de Tisbea acto seguido del episodio del Palacio real napolitano.

13. Tirso de Molina, El burlador, vv. 239-242.

14. Ibid. vv. 1150-1154.

15.Véase Enrica Cancelliere, "Lo femenino en el Burlador de Tirso de Molina», en Odette Gorsse y Frédéric Serralta (coords.) El Siglo de Oro en escena, Homenaje a Marc Vitse, Toulouse, PUM/Consejería de Educación de la Embajada de España en Francia, 2006, p. 141. 
La bella que resplandece como un ídolo andrógino, inalterable y satisfecho de sí, entre el espejo del cielo y el del mar, es una nueva Galatea que, orgullosa e incontaminada, se cree invulnerable a las flechas de Cupido.

La sublime pescadora repropone, en el ritmo de un romancillo heptasilábico, modulado por la sonoridad de las imágenes gongorinas, una melodía que reactualiza el topos de la bella desdeñosa, que finalmente verá castigado su desdén por los dardos del invencible dios. Precisamente este tópico, extensamente elaborado por los poetas espańoles, había sido formulado a fines del XVI por la canónica Silvia de Tasso, la insensible y arisca ninfa de Aminta, con acentos y motivos muy cercanos a los de Tisbea.

Aminta es también el nombre de la joven seducida por don Juan en la pastoral rústica del segundo y tercer acto del Burlador. El bodegón rústico está marcado por la presencia de las academias sienesas de los Rozzi y de los Intronati, presencia que está en el mismo origen de la Commedia dell'Arte partenopea, y que aflora también a menudo en el lenguaje de Tirso, junto con los preciosistas cultismos -irónicos en el contexto- de las Soledades. Por otra parte es cierto que Aminta es una hermosa villana y no un joven pastor como en Tasso, pero el nombre es una invención literaria tasesca.

También la fábula de El condenado por desconfiado como en parte la del Burlador tiene orígenes indoeuropeos; del Mahabarata procede el tema fundamental, el de la salvación y la perdición eternas del individuo puesto frente al gran misterio de la muerte, tema que en la época de la Contrarreforma toma nueva actualidad a través del debate sobre el libre albedrío. Paulo, santo eremita, recibe en su agreste ermita la visita del demonio disfrazado de ángel, que lo tienta sugiriéndole que vaya a Nápoles a la Porta del Mare, donde podrá observar al joven Enrico, cuya vida podrá revelar a Paulo la respuesta a una pregunta que le atormenta, esto es si al final de su existencia obtendrá la salvación. De la observación de la conducta de Enrico, Paulo sacará una conclusión descorazonadora: el joven es un malvado asesino y ladrón de la peor especie. Se decide entonces a volver a sus montes para dedicarse al crimen y al bandolerismo, entrelazando su destino con el de Enrico y sus maldades. Pero hay un detalle que se le escapa: a pesar de todas sus oprobiosas acciones Enrico ama a su padre con una absoluta devoción y únicamente los sufrimientos paternos -y no los propios- son la carcoma que le lacera el corazón. Esta es la luz de la salvación, pero Paulo, que un tiempo fue santo, cae en la total desesperación y muere entre las llamas del infierno maldiciéndose a sí mismo y a quien lo engendró.

Hay una correlación distintiva en las dos comedias en lo que sucede dentro de los muros en la ciudad y lo que sucede fuera, en la campiña, los montes o en la playa, correlación destinada a incluir metafóricamente en la obra el universo, pero del lado de los territorios literarios. De esta manera, la ciudad satisface los requisitos del lugar destinado para la tragedia y la comedia, requisitos unificados en esa tragicomedia que en España logra la hegemonía por medio de la fórmula teatral de Lope de Vega, teorizada por él mismo en el Arte nuevo de hacer comedias en este tiempo (1609). En cambio el tercer género del teatro -el pastoril 
o satírico- encuentra su escenario propio fuera de los muros. En el complejo de las dos comedias napolitanas Tirso revisa los tres subgéneros codificados: el piscatorio en el episodio de Tisbea, significativamente a continuación del inicio napolitano; el pastoral en la tipología rústica y campesina a continuación del gran escándalo sevillano; y la satírica o égloga ferina de los montes y las selvas que alterna en El condenado por desconfiado con los escenarios urbanos de Nápoles. Lo dicho hasta aquí presupone que las dos comedias se encuentran ligadas en sus dimensiones formales y temáticas por un diseño orgánico que se ha venido delineando entre dos bosquejos prácticamente coetáneos.

El homenaje a la Nápoles barroca de Domenico Fontana aceptada con sus valencias simbólicas se extiende ahora en El condenado por desconfiado para considerar la entera planta urbanística planeada por el arquitecto en el centro de la capital, ya que allí se desenvuelve la acción de las escenas urbanas de una comedia que no tiene una contextualización realista histórica y desarrolla su intriga en un metatiempo metafórico. Girando sobre la grandiosa realización del palacio Real, que acoge el principio del Burlador, el arquitecto regio ha abierto con un simbólico compás la via Chiaia hacia el monte, y la vía de Santa Lucía hacia el mar, instituyendo un espacio metropolitano frecuentado de una multitud interracial. A lo largo del eje que de la vía Medina lleva a los dos palacios, el angevino y el nuevo virreinal, ha colocado la fuente Medina o del Neptuno, y continuando el eje hasta el mar y el barrio de pescadores de Santa Lucía, el final de la vía homónima, otra fuente que toma nombre del barrio, erigida como un fascinante totem de puertas perforadas hacia el magnífico golfo.

Las dos preciosas obras han conocido las intervenciones de prestigiosos colaboradores: el arquitecto florentino Michelangelo Naccherino y el escultor Pietro Bernini autor de la estatua de la primera y de los monstruos marinos de la segunda. El hijo de Fontana, Giulio Cesare, será poco después en Madrid el más notable ingeniero ocupado de los sitios teatrales y de las escenas mutables de los espacios reales del Buen Retiro. Es suficiente para relacionar esta nueva Nápoles con el imaginario tirsiano.

No hay que olvidar el valor folclórico y simbólico del mencionado territorio urbano. La vasta plaza con jardines del Largo Castello al final de vía Medina era lugar de variadas formas de teatro callejero: cuentacuentos, malabaristas y acróbatas, máscaras de pantomimas y hasta promiscuas procesiones y danzas seudodevocionales por San Juan o Santa Lucía. El culto de esta santa se celebraba en el barrio homónimo la noche del 13 de diciembre, considerada la del solsticio de invierno.

Semejante contexto confiere a la mágica colocación de la fuente de Santa Lucía un valor propiciatorio, centro del cambio de las estaciones y de la luz en obsequio de fabulaciones tribales y rituales indoeuropeos filtradas por Escandinavia y por los normandos.

Exactamente como sucede en la comedia toda clase de gentes festejantes y deseosas de mostrarse se mezclaba en los muelles -el del la Immacolatella, Angioino, Beverello- mientras más allá de Santa Lucía, en Chiatamonte, 
acudían a las peligrosas cuevas de aquel lugar aquelarres de malhechores para divertirse y embriagarse mientras proyectaban toda clase de fechorías antes de mezclarse con la gente de toda clase social que llenaba la Puerta del Mar, o el espacio urbano ya mencionado que iba de un extremo al otro del diseńo sobre el mar de la muralla aragonesa que ceñía la ciudad.

En cuanto a los silvestres «napolitanos montes» que acogen las malandanzas de Enrico y del corrompido eremita Paulo basta pensar en el lejano Appennino Campano o en los montes Picentinos o de Irpinia.

Era pues una enloquecida cabalgata de diablos aquella que debían de componer los bergantes cuando decidían bajar de sus selváticas cuevas hasta el escenario urbano de sus delitos. Así lo declara el propio Paulo:

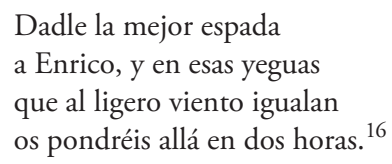

Pero ¿por qué todo comienza en Nápoles y en la Puerta del Mar?

Las influencias culturales, folclóricas y rituales del lugar lo convierten en el centro de una promiscua realidad metropolitana semejante a aquella que en el Burlador se atribuye a Sevilla y a Lisboa ${ }^{17}$. La Porta del Mare es, por estos mismos componentes, asimilada a un perno mágico del tiempo y del espacio, el umbral que puede dar lugar a sus opuestos, como la eternidad o la utopía.

En cualquier caso desde la visión de la Puerta del Mar en adelante, El condenado es una comedia de marco, comedia dentro de la comedia, como las de Andreini y Corneille, de modo que se podría pensar que todo lo que sigue -las brutales violencias de Enrico, la consiguiente perversión de Paulosean la visión o el delirio del eremita que no consigue encontrar a Dios, delirio engańoso y febricitante. Por lo demás el santo varón desgraciadamente no tocado por la gracia, dice nada más comenzar:

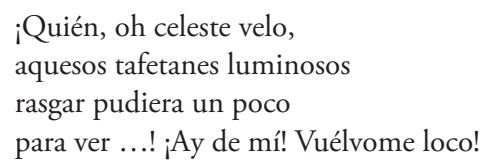

El demonio le invitará entonces a buscar la piedra angular de su desesperación en el lugar encantado que es la Puerta del Mar:

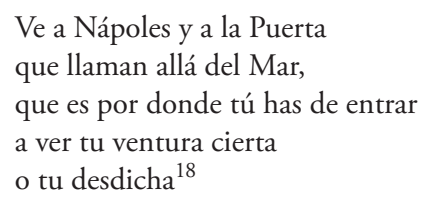

16. Tirso de Molina, El condenado por desconfiado, eds. Ciriaco Morón y Rolena Adorno, Madrid, Cátedra, 1978, vv. 2031-33.

17. Véase Marc Vitse, «La descripción de Lisboa en El Burlador de Sevilla», Criticón, 18, 1982, pp. 61-95.

18. Tirso de Molina, El condenado por desconfiado, vv. 258-261 
E inmediatamente lo induce a hacerse él mismo espectador de comedia en la comedia que seguirá:

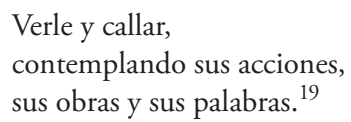

Al contrario, el criminal Enrico no necesita de visiones porque, sorprendentemente, posee en sí mismo toda la medida del misterio de la vida. Dirá al desesperado eremita:

Las palabras que Dios dice por un ángel, son palabras, Paulo amigo, en que se encierran cosas que el hombre no alcanza. ${ }^{20}$

No es casualidad que Enrico muestre en sus maldades el mismo coraje y la misma jactancia que Don Juan pero de signo invertido: venera la ancianidad, mientras que el otro la insulta. Dice a una víctima:

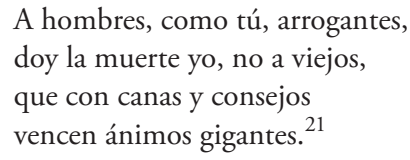

Este criminal que deliberadamente castiga a una clase social rica y lujuriosa, arrogante y expoliadora del pueblo, es el mismo que pone en su lugar la relación entre su subjetividad y el fantasma totémico que la constituye, restituyendo al padre anciano la connotación de la absoluta paternidad real y divina. De aquí la grandeza de una concepción del dar y del tener que no es mercantil, que no espera una igual compensación y que se expande hasta la relación con Dios para preguntarse: «¿Yo tengo que confesarme? / Parece que es necedad». ${ }^{22}$

Pero la Puerta del Mar se abre también a la inversión de todo esto: a lo repugnante, a lo carnal, a lo obsceno. La cortesana Celia implora a Enrico, su protector, que la lleve de paseo para que pueda mostrarse a la admiración de los demás como las otras cortesanas y los rufianes puedan presumir de ellas, aunque después las maltraten vilmente para sacarles el botín. Allí dominan los lenguajes de la mala vida, las jergas obscenas equivalentes a la germanía sevillana, como ironiza en una pelea el sangriento bandolero Galván:

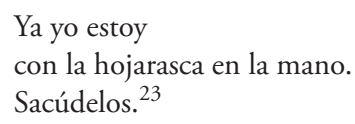

19. Ibid., vv.276-78.

20. Ibid., 1961-64.

21. Ibid., vv. 1321-24.

22. Ibid., vv. 2383-84.

23. Ibid., vv. 497-99. 
Y allí Enrico arroja al mar un pobre mendigo y marca a las hermosas que no le tributan:

\author{
Las mujeres estafaba; \\ y no dándome dinero, \\ visitaba mi navaja \\ su rostro luego al momento. ${ }^{24}$
}

evocando sangrientos ritos de valentones que luego se prolongarán en las escenas napolitanas.

Para los criados, como Pedrisco, aquel atestado territorio urbano está hecho de tabernas: el Bodegón de Juanilla, la Taberna del Tuerto (vv. 327-28), donde campea el tabernero gordo. Todos ellos se reúnen en la Puerta del Mar en un círculo grosero y alborozado para escuchar las atrocidades de los bandoleros, contadas con arte y movimiento, de manera que Enrico recibe la corona de laurel del máximo de los poetas por sus relatos de horror.

De esta Nápoles parte en la diégesis un infinito movimiento, centrífugo en la primera comedia y centrípeto en la segunda, como para encerrar el cosmos entero en su torbellino.

El deseo, en suma, única realidad verdaderamente incontenible del universo tirsiano reside en el "error" de los personajes y el error es agustinianamente, un "errar", un movimiento que recomienza siempre y excava a una profundidad inexplicable. No importa que conozcamos solo cuatro víctimas del burlador: cuatro es la numeración que recomienza, infinita por tanto: es ya la lista de Da Ponte.

El Otro, el tótem, el ídolo es todavía y de nuevo el fantasma del deseo, pero en su cara nocturna; de hecho la audacia y arrogancia de don Juan, Paulo, Enrico, proceden errando de modo diverso en lo inaccesible, lo nocturno, de valerosos héroes armados de espada y de juventud, llevando la vida y la luz del día y allí, en la Alteridad, apagándola temerariamente por el encanto, sea de la fe y la redención -Enrico-, o al contrario, de la desesperación -en Paulo- o quizá temeraria a ultranza en el aferrar y estrechar una mano fría, la mano del Otro, en don Juan.

Esta Alteridad es piedra ajena a la vida, estatua, totem o Puerta, que se constituye en pivote que cierra y abre el territorio Otro, en el cual es posible errar hasta el infinito en la experiencia infinitamente compleja de la nada y por eso territorio de una densa fascinación, de innumerables vías que basculan entre el orden y el caos, el espíritu y la carne, la vida y la muerte, la luz y la oscuridad, territorio de una seducción fatal que en Tirso se llama Nápoles. 